\title{
RECONSTRUCTION AND USE OF THE SUCCESSION OF THE BALTIC SILURIAN OSTRACODES
}

RUBEL, Madis, Institute of Geology, University of Tartu, EE 2400, Estonia

Since Smith's days successions or biozones of fossils have been widely used in stratigraphy in aid to give the relative age of the rocks. Nevertheless, two questions may be raised: (1) how to arrange the observations into purely temporal succession and, (2) how to apply the got succession of taxa. The last three decades gave many algorithms, dedicated to solution of these mutually tied tasks. It became evident that there exists more than one solution (succession) for the same data set. The successions got by strict numerical methods, may be used as time scales with all their qualities even in case of their ordinality.

In studies of the Baltic Silurian the quantitative methods have been applied also. This sequence, stratigraphically continuous, comprises 500 metres of carbonate rocks, with well-preserved fossils as it has been established by many thousand of boreholes. The subsurface investigations have extensively updated the paleontological record, especially that of microfossils, but they have brought out a need to define more exactly the traditional regional stratigraphic units. The data set by L.Sarv, L.Gailite, N.Sidaraviciene and others includes the distributional data on about 300 species of ostracodes from nearly 100 sections (forty-four boreholes inclusive). These data have arranged into a paleontological time scale by the algorithm DISTR by Rubel and Pak, using the order and coexistence of species as observed in sections. Two principal scales can be revealed: (1) the first one was composed of the most widespread but few species, (2) the second one contained more species but did not include all widespread species. The latter scale includes many species in common with the latest Silurian zonal scheme in the same order but the scale contains about three times more datum planes than the zonal scheme. Nevertheless, the scale is not a simple substitute of the scheme; the scale can be regarded as much more effective tool for the chronostratigraphic classification of the sections than any existing ostracode zones.

The Baltic regional stages have been always based on paleontological evidence. Thus, the ostracode zonal scheme, discussed here, actually specifies each stage by an index species or one to two zones (assemblages). As the key species occur also in the succession mentioned, then it can be subdivided by them into intervals corresponding to these stages. Unfortunately, zonal schemes of other fossils used to specify the stages in the same way, give unambiguous boundaries between the stages, which do not coincide then with each other. An attempt to define the regional stages by the appearance of some archistratigraphical fossils showed this disconcordance clearly. However, this attempt took a step to apply the boundary stratotype concept in the regional chronostratigraphy, in which paleontological time scales, like to the ostracode one, have obvious advantage. 